\title{
SABERES EXPERIENCIADOS NO BAIRRO ALTO JOSÉ DO PINHO (RECIFE/PE): BEM VIVER COMO ALTERNATIVA AO DESENVOLVIMENTO
}

\author{
KNOWLEDGE EXPERIENCED IN THE "ALTO JOSÉ DO PINHO NEIGHBORHOOD" \\ (RECIFE/PE): "BEM VIVER" AS AN ALTERNATIVE TO DEVELOPMENT
}

Anne Gabriele Alves GUIMARÃES ${ }^{1}$, Vanessa Barros Correia de Carvalho MACÊDO², Clarissa MARQUES ${ }^{3}$

Artigo recebido em 20/07/2020, aceito em 14/06/2021, publicado em 14/07/2021.

\begin{abstract}
Bem Viver;
Alto José do Pinho;

Alternativas ao

desenvolvimento;

Capitalismo.

RESUMO

O presente artigo busca analisar a relação entre o Bem Viver enquanto alternativa ao desenvolvimento e as práticas cotidianas do bairro Alto José do Pinho em Recife/PE a partir de uma abordagem qualitativa, com viés bibliográfico, descritivo-explicativo e exploratório. 0 estudo está fundamentado nos aportes fornecidos por Ibáñez (2016), Acosta (2016) e Lang (2016). Ressalta-se que o contexto urbano, apesar da matriz colonial pautada pelo modo de produção capitalista, também comporta novos modos de vida elencados como Bem Viver. A experiência do Alto José do Pinho reflete a tentativa de resgate de valores ancestrais, desmercantilizando as relações humanas e aproveitando o tempo livre. O Bem Viver, neste caso concreto, é sinônimo de transformação, pois enaltece o sentimento de pertencimento construído a partir de estratégias populares.
\end{abstract}

\section{ABSTRACT}

Keywords:

Bem Viver;

Alto José do Pinho;

Alternatives to

development;

Capitalism.

This article seeks to analyze the relationship between "Bem Viver" as an alternative to development and the daily practices of the "Alto José do Pinho neighborhood" in Recife/PE from a qualitative approach, with a bibliographical, descriptive-explanatory and exploratory bias. The study is based on the contributions provided by Ibáñez (2016), Acosta (2016) and Lang (2016). It is noteworthy that the urban context, despite the colonial matrix guided by the capitalist mode of production, also contains new ways of life listed as "Bem Viver". The experience of Alto José do Pinho reflects the attempt to rescue ancestral values, demercantilizing human relations and taking advantage of free time. "Bem Viver", in this specific case, is synonymous with transformation, because it extols the feeling of belonging built from popular strategies.

\footnotetext{
1 Pós-graduanda em Direito Público pela ASCES/UNTA (Caruaru/PE). Advogada. Pesquisadora do Grupo de Estudos e Pesquisas Transdisciplinares sobre Meio Ambiente, Diversidade e Sociedade (GEPT/UPE/CNPq). Orcid: https://orcid.org/0000-0003-1950-2417. E-mail: annegabrieleguimaraes@gmail.com.

${ }^{2}$ Graduanda em Direito pela Faculdade Damas da Instrução Cristã (Recife/PE). Pesquisadora do Grupo de Estudos e Pesquisas Transdisciplinares sobre Meio Ambiente, Diversidade e Sociedade (GEPT/UPE/CNPq). E-mail: vanessabccm4@gmail.com.

${ }^{3}$ Pós-Doutora na The New School of Social Research - NY. Professora da UPE Arcoverde e da Faculdade Damas da Instrução Cristã. Coordenadora do Grupo de Estudos e Pesquisas Transdisciplinares sobre Meio Ambiente, Diversidade e Sociedade (GEPT/UPE/CNPq). Orcid: https://orcid.org/0000-0003-2567-141X. E-mail: marquesc2504@gmail.com.
} 


\section{INTRODUÇÃO}

A análise do Bem Viver enquanto oportunidade de construção coletiva de novas formas de vida está intimamente ligada às propostas de alternativas ao desenvolvimento concebidas no seio dos grupos tradicionalmente marginalizados. Neste sentido, o presente trabalho ressalta a necessidade de recuperar experiências e lições negadas pelo padrão civilizatório hegemônico. Para tanto, destaca o caso do bairro Alto José do Pinho, localizado em Recife/PE, uma maneira de conhecer, pensar e existir que, apesar de estar inserido no contexto de aceleração consumista da metrópole, destoa dele ao reconhecer os bons viveres, baseados na aprendizagem coletiva e nas práticas cotidianas.

As alternativas ao desenvolvimento, evidenciadas pelo referido bairro, são multiformes e possuem sujeitos diversos, visando superar não apenas a relação capital-trabalho, mas também romper com as dimensões patriarcais e de destruição da natureza.

Investigar a relação entre o Bem Viver e as experiências do Alto José do Pinho implica em desconstruir, reconfigurar e reabitar a cidade, neste caso, Recife, tomando como base outros modos de vida que nela coexistem. Tal proposta é estudada a fim de resgatar os lugares de convivência, os locais de encontro, escassos na cidade contemporânea/imperial/colonial.

As lições trazidas pelo Alto tornam possível a transformação de hábitos em tempo presente, alicerçada na confluência de experiências concretas advindas de estratégias populares, o que se relaciona à uma outra noção de comunicação como estudo de agentes e meios marginalizados.

Os planos de vida aptos a enfrentar a crise do padrão civilizatório hegemônico são pensados através de formas diferentes de produzir, distribuir e estabelecer relações sociais. Por isso, o Bem Viver convida a refletir sobre formas de sociabilidade e pertencimento não relacionadas à mercantilização, mas à emancipação e gestão conjunta. Ademais, o debate deve ser estendido para além da mudança do modelo estatal, alcançando também o horizonte civilizatório.

Nas alternativas ao desenvolvimento, o Estado não tem o papel central, tendo em vista que os bons viveres realizam-se principalmente nas relações interpessoais. Transitar para outros modos de vida, dentro do contexto urbano, ou seja, na e a partir da própria cidade, sem sair dela, significa driblar a armadilha desenvolvimentista calcada no capitalismo. É dentro do bairro analisado que os moradores se reinventam sob a ótica da diversidade e da pluralidade. Assim sendo, criam a noção de redistribuição voltada à igualdade e à harmonia.

\section{MÉTODO}

O método utilizado para desenvolver o trabalho é o indutivo, uma vez que a pesquisa estuda o caso do Alto José do Pinho para identificar novos modos de vida experimentados dentro da cidade. 0 
procedimento selecionado investiga se é possível criar horizontes de sentido ou modos de vida menos acelerados e mais saudáveis.

No tocante à natureza desta pesquisa, introduz-se uma abordagem qualitativa, uma vez que usa dados em busca do seu significado, no intuito de compreender os fenômenos propostos dentro do seu contexto. Utiliza-se, ainda, os tipos de pesquisa bibliográfico, descritivo-explicativo e exploratório. 0 instrumento de coleta de dados aqui selecionado é a revisão de literatura.

Como técnica de análise de dados, utiliza-se a análise de conteúdo, por ser mais ampla, permitindo uma abordagem mais diversificada dos fenômenos. A escolha desta técnica justifica-se pelo fato de a mesma reunir um conjunto de instrumentos metodológicos sutis e em constante aperfeiçoamento, podendo aplicar-se a discursos e conteúdos diversificados.

\section{RESULTADOS E DISCUSSÃO}

\subsection{América Latina enquanto laboratório de alternativas}

A América Latina vem atravessando nos últimos anos uma conjuntura peculiar no contexto global. Tal conjuntura permite dizer que a região vem se transformando em um verdadeiro laboratório de alternativas. Isto porque grupos e coletivos culturais estão promovendo discussões profícuas acerca das alternativas ao desenvolvimento.

Lang (2016) estabelece que estas alternativas visam questionar problemas estruturais da sociedade latino-americana, sobretudo a dependência primário-exportadora em relação ao mercado mundial. Os múltiplos processos sociais trabalhados enquanto "alternativas" vislumbram cenários concretos de transição, capazes de fortalecer os controles ambientais, a redução gradual da extração de bens naturais, a democratização e a transformação dos padrões energéticos e tecnológicos e a desmercantilização da natureza.

Estas novas perspectivas de ser, viver e fazer se organizam a partir de uma autonomia relativa em relação ao Estado, pois representam resistência a empreendimentos extrativos ou a megaprojetos funcionais, muitas vezes financiados pelas forças estatais. "Em muitos casos, defender um modo de vida relativamente autossuficiente e resistir a ser espoliado das condições materiais que o tornam possível já representa em si mesmo uma alternativa ao desenvolvimento" (Lang, 2016, p. 42).

Nessas estratégias populares, a produção, o controle e a defesa do território se tornaram centrais. Em vez de participar docilmente na elaboração institucional de "planos de desenvolvimento", muitos territórios colombianos, por exemplo, decidiram elaborar planos de vida a partir de baixo, ou seja, pensar formas diferentes de produzir, distribuir, estabelecer relações sociais, organizativas e comerciais. Nesses planos, o Estado não tem o papel central, mas o contrário: dele somente se espera que deixe fazer, que permita a autogestão do território (Lang, 2016, p. 42). 
Na América Latina, os diferentes processos de autonomia indígena, as lutas camponesas pela soberania alimentar e os múltiplos processos organizativos em bairros populares são considerados alternativas ao desenvolvimento. Em suma, constroem rapidamente novas formas de sociabilidade, novas comunidades políticas e sentidos de pertencimento, criando "novos comuns" em vez de mercantilizar.

Tais experimentações sociais convidam à autogestão, à emancipação, a tomar a vida com as próprias mãos, não de maneira individual, e sim conjuntamente com outros. Ademais, as alternativas ou transições são multiformes e têm sujeitos diversos. Seus horizontes são os bons viveres, no plural, sempre contextualizados, baseados na aprendizagem coletiva, buscando superar as dimensões do patriarcado, do colonialismo e das relações depredadoras com a natureza (Lang, 2016).

É preciso questionar o próprio conceito de desenvolvimento e construir alternativas ao atual modelo de desenvolvimento hegemônico e a transformação não é algo que se espera para um futuro longínquo, mas se dá em tempo presente, com a transformação das subjetividades, das relações interpessoais e das práticas cotidianas.

Sobre a necessária transformação de subjetividades, cabe mencionar a lição de Ailton Krenak (2020), para quem todos os seres vivos possuem valor próprio, o qual não pode ser mensurado de acordo com sua utilidade para as aspirações humanas. Segundo ele, a Natureza é a interação do corpo com o entorno a partir da cosmovisão da Terra como um organismo vivo (Krenak, 2020).

No sistema de proteção à vida não há que se falar em hierarquia. 0 homem é tão importante quanto a Natureza. Ele - o homem - não pode se sentir superior em relação aos seres que existem no meio natural ao seu redor. É necessário que haja um sentimento de pertença por parte do ser humano, como uma peça de toda biosfera, e como tal deve se colocar. 0 respeito mútuo entre os seres humanos deve se estender para abranger 0 respeito aos seres vivos em geral, ou seja, o respeito a todos habitantes do mesmo espaço (Pontes Júnior \& Barros, 2016, pp. 441-442).

Deve ser incorporado nas práticas cotidianas o respeito ao meio ambiente e aos elementos humanos e extra-humanos. Neste sentido, a preservação do meio ambiente exige um olhar interdisciplinar a partir de práticas comunitárias de educação ambiental, por exemplo.

Entende-se, para os fins deste trabalho, que a educação ambiental é um instrumento de luta política, cujo nível mais poderoso de transformação se revela em uma disputa de posições e proposições sobre 0 destino das sociedades, dos territórios e das desterritorializações, acreditando que, para além do conhecimento técnico-científico, o saber popular igualmente consegue proporcionar caminhos de participação para a sustentabilidade (Sato, Gauthier, \& Parigipe, 2005).

$\mathrm{Na}$ perspectiva das alternativas ao desenvolvimento, é possível desenvolver ações locais que tornem as pessoas mais críticas e conscientes a respeito de suas próprias necessidades e do que essas necessidades podem causar ao meio em que vivem. O papel da educação ambiental, neste sentido, é 
contribuir para o desenvolvimento de uma consciência crítica e estimular o enfrentamento das questões ambientais e sociais.

Parte-se, ainda, do entendimento de que a formação de consciências (comunitárias) críticas é capaz de despertar um sentimento de solidariedade entre as gerações, já que a preservação do meio ambiente é essencial para que existam vidas futuras. A preocupação é não somente com as gerações atuais, mas também com as futuras - caráter transgeracional (Marques, 2013).

Enquanto laboratório de alternativas, a América Latina vem trabalhando não apenas a mudança cultural, mas também a transformação social. Por esta razão, não se fala em "desenvolvimentos" alternativos, mas sim em alternativas ao desenvolvimento, rechaçando, como ponto de partida, o rótulo de "subdesenvolvidos".

As experiências acerca de alternativas buscam recuperar saberes das múltiplas cosmovisões que existem, reconhecendo e reconstruindo uma diversidade de modos de vida - no campo e nas cidades diante da expansão do modo de vida imperial. São experiências contra-hegemônicas que caminham na contramão do padrão civilizatório estabelecido pelo modo de produção capitalista.

Assim, "a solução não radica em um 'desenvolvimento' diferente, sustentável, equitativo, inclusivo: porque a própria noção de 'desenvolvimento' - se a olharmos a partir dos fatos gerados - contradiz os conceitos de sustentabilidade, de equidade, de inclusão" (Lang, 2016, p. 31). O desafio aqui proposto, então, é dar visibilidade aos bons viveres latino-americanos na esperança de que estas práticas possam inspirar outros processos de mudança no contexto latino-americano.

\subsection{Alto José do Pinho: experiência de gestão coletiva}

Não é comum encontrar nas grandes cidades o clima do Bem Viver. Geralmente os cidadãos, associados a consumidores, perdem os costumes dos seus antepassados, sendo as relações cada vez mais superficiais. O modo de vida acelerado imposto pelo capitalismo faz desaparecer os lugares de convivência, como mercados populares, feiras e espaços de diversão familiar. Em outras palavras, "apagam-se os locais de encontro, desabita-se a rua e se privatiza a reunião" (Ibáñez, 2016, p. 312).

O descarte crescente e o consumismo são as marcas da cidade contemporânea, caracterizada por carregar 0 imaginário capitalista, desenvolvimentista e colonial. 0 urbano globalizado aprisiona o tempo livre (Ibáñez, 2016). Isso ocorre, pois a cidade é sistematizada de forma a priorizar o lucro constante para atender aos anseios financeiros.

Neste sentido, Ibáñez (2016, pp. 310-311):

A noção de comunicação se desloca da ideia de espaço de compartilhamento para a aceleração do deslocamento de maneira a facilitar os consumos e o efêmero, que já não comunica, e sim consome. As ruas deixam de ser meios de comunicação, no sentido de locais de convivência pública. Recordemos que as calçadas eram um espaço de encontro, 
com os bancos nos portões das casas, ou as pedras colocadas para se sentar e ver as pessoas. Agora as ruas passam a ser vias de "comunicação", na medida em que permitem acelerar o trânsito dos carros e pedestres. Não são mais um lugar para ficar, mas sim para passar de um lugar de consumo a outro. O mesmo acontece com o critério de praça, que, em seus modelos de construção, muda: de lugar de encontro, para dias de "campo de domingo", de lugar para estar, converte-se em espaço de passagem ou então de eventos.

A mídia também tem uma relevante participação nesse processo, uma vez que atua como corpo docente da sociedade atual, reproduzindo diariamente a ideia de consumismo, mecanizando e manipulando as relações humanas.

O bairro Alto José do Pinho, em Recife/PE, por sua vez, caminha na contramão de tal matriz colonial. Localizado às margens da Estrada de Ferro, eixo norte, atual Avenida Norte, o Alto José do Pinho foi um dos primeiros morros a ser ocupado (Silva, 2011). De acordo com último censo possui cerca de 12.334 habitantes (IBGE, 2010).

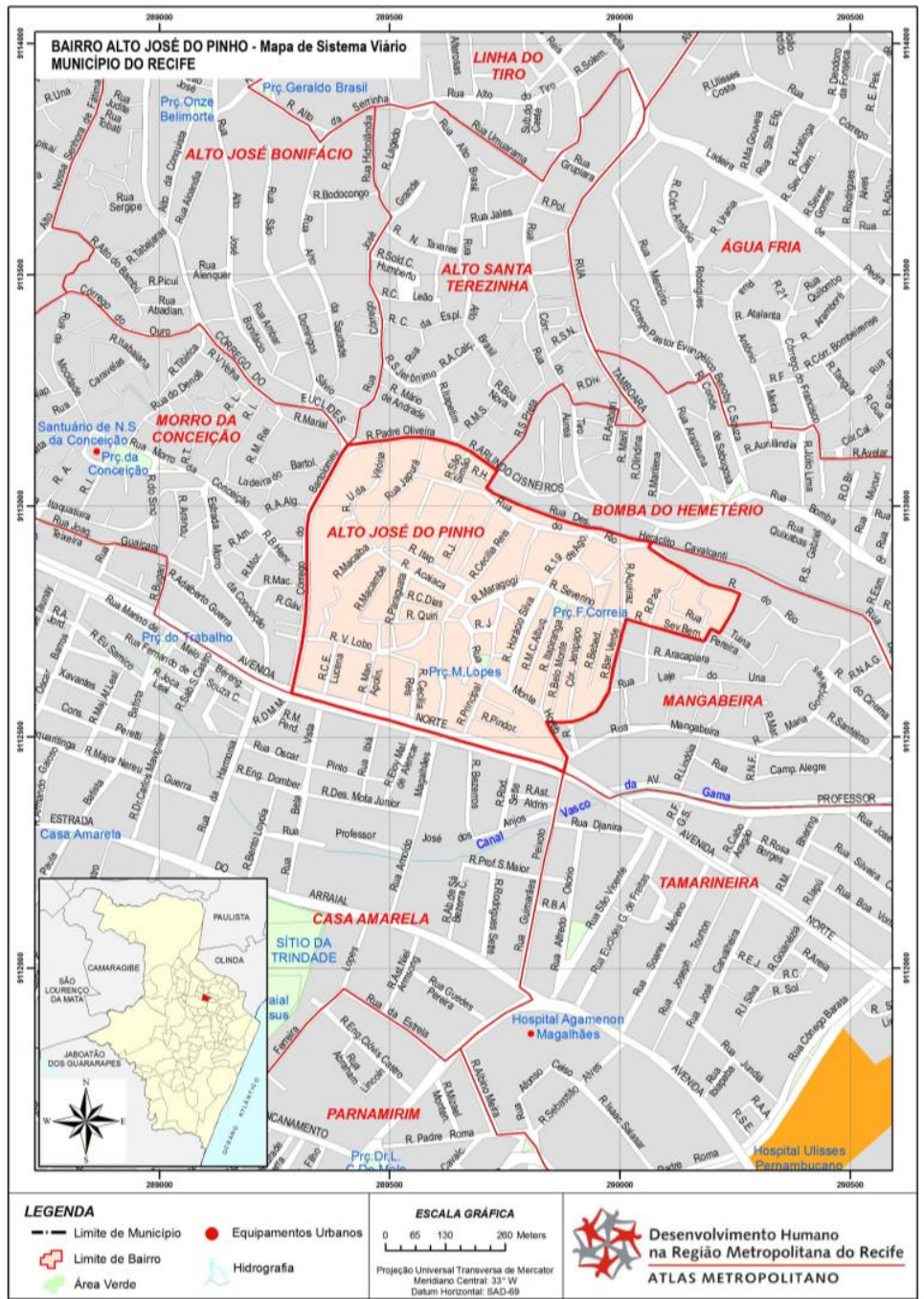

Figura 1 - Mapa da localização do bairro Alto José do Pinho

Disponivel em: http://www2.recife.pe.gov.br/servico/alto-jose-do-pinho?op=NTI4Mg== 
Seus moradores procuram aproveitar o tempo livre valorizando e respeitando as culturas dos antepassados através do maracatu rural, do jogo de futebol nas ruas e da música, que é o instrumento utilizado pelos grupos marginalizados na tentativa de fazer comunicação alternativa à mídia massiva (Ferreira, Sousa \& Lima, 2017), pois informa e critica, legitimando ideias sobre o mundo.

Neste sentido, tem-se a banda de punk rock Devotos, nascida no Alto José do Pinho, com mais de 25 anos de carreira. A banda, que já tocou nos principais festivais nacionais e fez três turnês na Europa, reivindica através da arte e, mesmo com a vasta carreira, o lugar que nunca sai do seu imaginário urbano é 0 bairro de origem. Deste sentimento de pertencimento, surgiu a rádio comunitária do local. 0 objetivo é fomentar 0 intercâmbio de informações, ideias e opiniões advindas dos públicos marginalizados (Beltrão, 2014). Por isso, diz-se que a noção de produção coletiva e compartilhada, inerente à experiência do Bem Viver, se faz presente no bairro.

Vale salientar que o estilo punk rock brasileiro demorou muito a ser aceito no Alto José do Pinho, porém, quando as pessoas entenderam o objetivo da banda, passou-se a reconhecer principalmente 0 valor dos agentes culturais que, politicamente ativos, movimentam-se em extensas redes de comunicação, alterando os rumos das escolhas que influenciam a convivência (Mergulhão, 2017).

Abaixo, intenta-se trazer em imagens as vidas em movimento do Alto, permitindo ao leitor sentir e apreender como se perfazem os modos de vida no local. Enfatiza-se, inclusive, o simbolismo das cores presentes em escadarias e as mensagens em cartazes nas escolas.

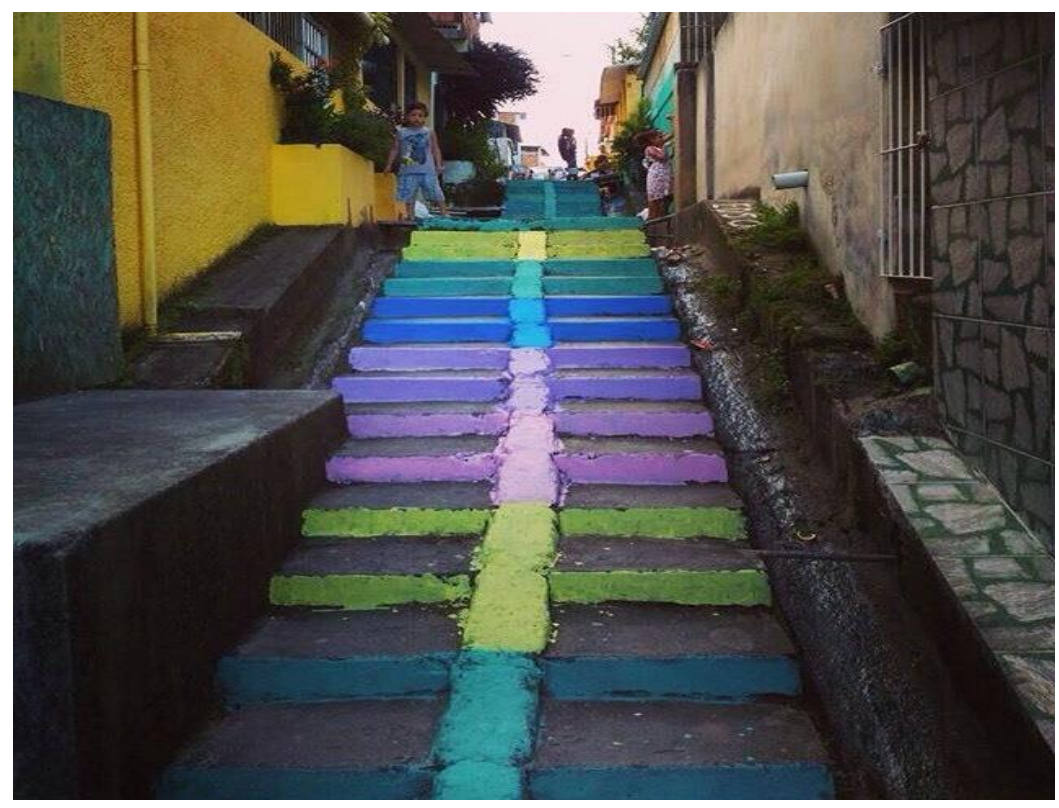

Figura 2 - Escadaria no Alto José do Pinho Disponível em: https://www.instagram.com/altosustentavel/ 


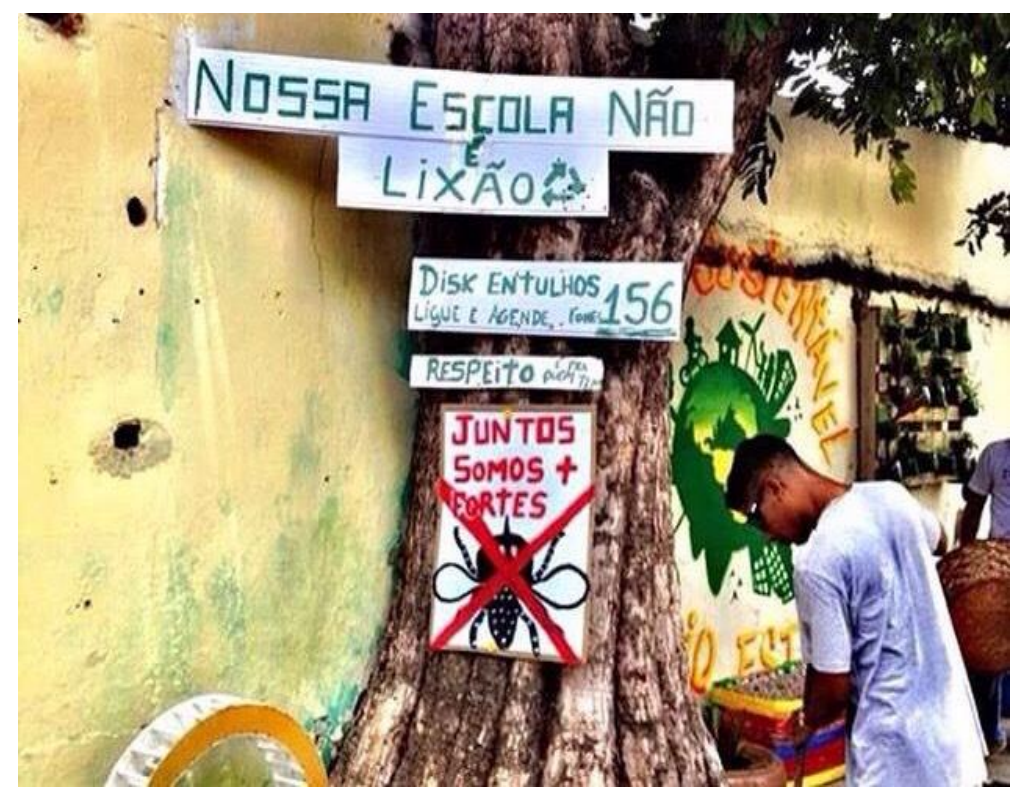

Figura 3 - Campanhas educativas em escola do bairro Fonte: Disponível em: https://www.instagram.com/altosustentavel/

As fotos tendem a revelar o contexto das relações locais com o mundo material e imaterial, a fim de fazer refletir acerca das perspectivas concretas de mudança social a partir das territorialidades. As formas de retratar o Alto José do Pinho neste trabalho, entretanto, não esgotam a totalidade de ações/intervenções lá desenvolvidas. São, na verdade, tentativas de simbolizar o cotidiano múltiplo e plural protagonizado pelos populares, ou seja, forjado "de baixo para cima".

A relação tão próxima entre os moradores, comum nos bairros suburbanos, faz lembrar o modo de vida desacelerado do interior. A solidariedade entre os moradores do Alto é comum, por exemplo, quando algum deles está com problema de abastecimento de água. Procura-se, então, fazer reuniões para solucionar a questão junto à Companhia Pernambucana de Saneamento (COMPESA). Ademais, o bairro conta também com o Projeto Alto Sustentável, que trabalha com coleta seletiva e criação de jardins verticais com garrafas pets, conscientizando o público para a prática de bons viveres sustentáveis. 


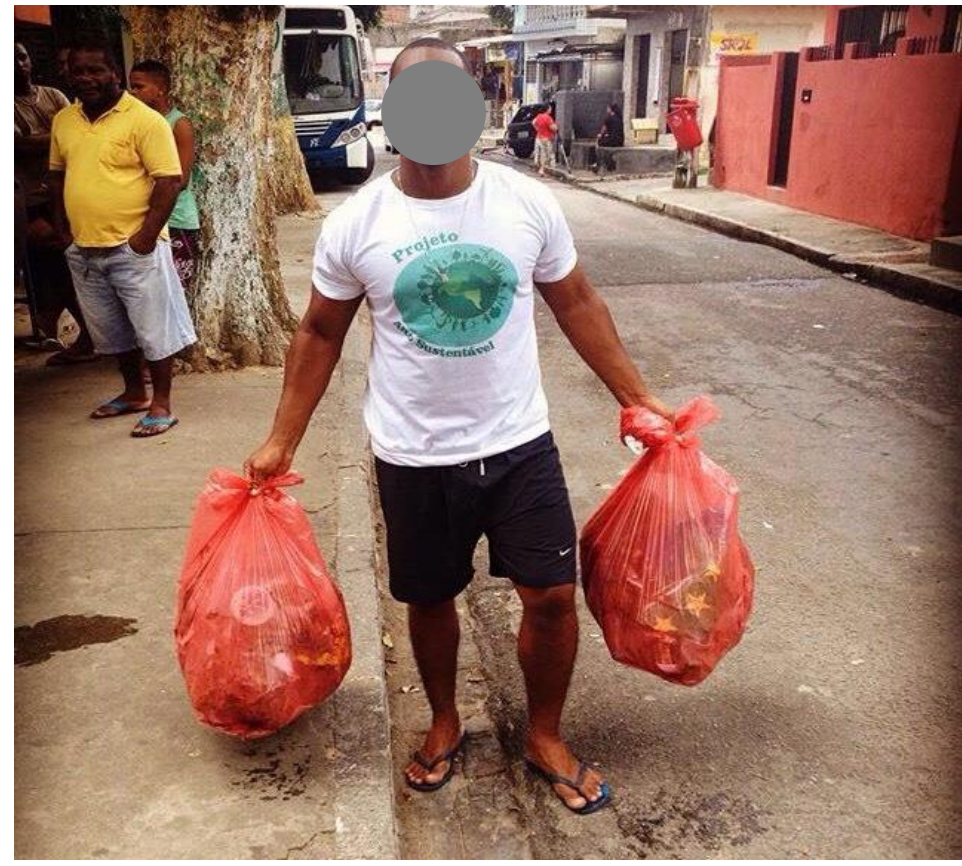

Figura 4 - Morador do Alto José do Pinho em ação do Projeto Alto Sustentável Fonte: Disponivel em: https://www.instagram.com/altosustentavel/

Os bons viveres acima mencionados tornaram o Alto mais conhecido nas páginas culturais do que policiais, conquista essa pautada na luta e na resistência. Atualmente não só a mídia vai ao local como os próprios moradores sentem orgulho em falar das suas origens. Em outras palavras, esteticamente 0 Alto continua o mesmo, mas o imaginário das pessoas foi transformado. Agora elas querem fazer a sua história, acreditam em si e acreditam no lugar onde vivem, sentimento despertado graças à interação social promovida pelos grupos culturais locais, como a banda Devotos.

O bairro, suas ações e dinâmicas materiais, simbólicas e afetivas representam a tentativa de construir outros mundos, outras possibilidades de viver, ser e pensar. É possível, ainda que em contextos urbanos, ousar romper com o padrão civilizatório hegemônico capitalista, que prioriza o progresso ilimitado em detrimento das potencialidades da vida humana.

É urgente uma ruptura civilizatória e epistêmica, pensar em utopias concretas, realizáveis territorialmente e localmente, das bases populares, dos coletivos culturais. O Alto José do Pinho não só mostra que tais práticas são possíveis como realizáveis. A mudança de imaginário começa, portanto, quando aquela sociedade se identifica e se percebe enquanto corpo político e agente de mudanças estruturais.

Percebe-se, neste processo de vivências e saberes, que o uso do espaço é capaz de definir o território (Santos, 1996). Logo, dado território pode ser "abrigo" ou "recurso" a depender de como as relações são nele desenvolvidas, sejam de pertencimento ou de exploração. Assim:

[...] território abrigo, espaço vivido e chão da morada, patrimônio dos vivos, dos mortos e dos que virão nascer, onde a natureza é mãe e progenitora, apropriada pelo trabalho familiar e comunitário para a sustentação da vida (material, simbólica e afetiva); e território recurso, espaço unifuncional onde a natureza e o trabalho são explorados e transformados 
em mercadoria, no intuito de gerar a acumulação desigual de riquezas (Ferreira, 2016, p. 270 , grifos do autor).

O Alto José do Pinho é o vivo exemplo de território-abrigo, território de pertencimento, cuja essência se encontra em uma matriz de racionalidade diversa da apregoada pelas lógicas capitalistas. As lutas lá forjadas implicam em participação democrática e consciência coletiva de bairro como corpo político.

Suas particularidades constituem exemplos de bons viveres, de novas pedagogias contrahegemônicas, na contramão do desenvolvimento enquanto apropriação de corpos e força de trabalho. Por fim, não se quer aqui romantizar, mas apontar para novas possibilidades de "mundos" em um cenário de fissuras e fragmentações.

\subsection{Bem Viver: o convite a pensar outros mundos}

O padrão civilizatório ocidental passa por uma crise. Significa dizer que sua dinâmica baseada na mercantilização da vida desafia os limites do planeta. Segundo Lander (2016, p. 216), "se em pouco tempo não conseguirmos colocar freios a essa engrenagem de destruição sistemática, o que está em jogo com 0 colapso final do capitalismo é a sobrevivência da humanidade".

É com o propósito de apresentar alternativas ao desenvolvimento, este último caracterizado por proporcionar luxo a uns e espoliação de tantos outros de acordo com as lógicas do capital, que o Bem Viver se apresenta enquanto tarefa descolonizadora. É, sobretudo, um convite a repensar as maneiras de relacionamento entre os elementos humanos e extra-humanos, "de forma a favorecer uma vida que flua para todos e para todas" (Ibáñez, 2016, p. 321).

A relação entre os homens e a natureza, portanto, é uma forma de minar o padrão desenvolvimentista, seguindo o exemplo dos povos indígenas, cujas culturas nascem com base na ancestralidade com os ciclos naturais. Da vida rural destes povos extraem-se as fontes para pensar o Bem Viver.

Acerca deste horizonte de sentido, afirma Acosta (2016, p. 73):

Forja-se nos princípios de interculturalidade. Vive nas práticas econômicas e solidárias. E, por estar imerso na busca e na construção de alternativas pelos setores populares e marginalizados, terá de se construir sobretudo a partir de baixo e a partir de dentro, com lógicas democráticas de enraizamento comunitário.

Afirma-se que o Bem Viver repensa as noções de pobreza e riqueza por meio de estratégias populares, sendo "um sentido que exige capacidade de construir, inventar, criar e permitir a germinação do existente, que reconfigura a dominação de outros horizontes. Não é possível sem diversidade e pluralidade" (Ibáñez, 2016, p. 321).

O desafio apresentado, neste contexto, é a possibilidade de desenvolver experiências de bons viveres dentro do contexto urbano. Não se pode ressignificar a cidade a partir de bases coloniais. Isto seria 
manutenção das relações dominantes. A questão é ressignificar a cidade sem sair dela, de maneira conectada com o rural/indígena.

Na América Latina, algumas pessoas habitantes da cidade já começam a reproduzir maneiras de viver baseadas na origem indígena. A tentativa de romper com o hegemônico, as práticas populares na contramão do sistema capitalista imposto, as articulações sobre alternativas ao desenvolvimento. Este é o horizonte de sentido do Bem Viver.

Tal transformação civilizatória encontra espaço no tempo presente a partir de práticas cotidianas. Uma delas, elencada como estudo de caso da pesquisa, é o sentimento de pertencimento existente no Alto José do Pinho, em Recife/PE.

O Bem Viver, seja no exemplo dado ou em outras experiências, demanda a construção de propostas. Neste sentido, Acosta (2016, p. 33):

Com sua proposta de harmonia com a Natureza, reciprocidade, relacionalidade, complementariedade e solidariedade entre indivíduos e comunidades, com sua oposição ao conceito de acumulação perpétua, com seu regresso a valores de uso, o Bem Viver, uma ideia em construção, livre de preconceitos, abre as portas para a formulação de visões alternativas de vida.

Longe de um plano pronto e acabado, deve ser considerado parte de uma longa busca de alternativas de vida forjadas no calor das lutas populares, principalmente dos povos e nacionalidades indígenas (Acosta, 2016). É um convite a discutir ideias surgidas de grupos tradicionalmente marginalizados, excluídos, explorados e até mesmo dizimados. O Bem Viver é sinônimo de resistência ao colonialismo e suas mazelas. Está bem distante de uma tradução livre associada ao viver melhor, pois este último pode levar ao acúmulo de bens, ao progresso material ilimitado.

Diante de um cenário multifacetado, marcado por uma crise civilizatória que põe em xeque os limites do planeta, nos interesses recuperar as lições dos saberes indígenas, mais ainda, torna-se urgente a reconfiguração dos imaginários urbanos para além da visão desenvolvimentista.

A cidade que reflete a crise do padrão civilizatório hegemônico é a mesma que tenta se desvincular da dinâmica destrutiva da mercantilização da vida. O Bem Viver, portanto, nasce nos contextos urbanos. É preciso estar atento à diversidade de elementos presentes nestas ações populares. Entre eles, 0 conhecimento, os códigos de conduta ética e espiritual em relação ao entorno, os valores humanos e a visão sobre o futuro (Acosta, 2016).

A desconstrução do espaço urbano a partir deste horizonte de sentido se dá, como primeiro exemplo, pela ocupação de territórios ou terrenos baldios frutos da especulação imobiliária. Surgem novos modos de vida, no centro da cidade, propondo novas convivências. Este é o exercício do direito à cidade. Não basta penetrar naquele espaço, mas transformar as relações. 
As feiras, por sua vez, têm um caráter relacional e afetivo. Nelas, a lógica que prevalece é a da freguesia, a convivência com os que transitam por lá. Dentro de um mundo onde tudo é cercado por muros (da segregação), as feiras ocorrem ao ar livre.

Outra experiência baseada no Bem Viver vem dos bolsões da população boliviana. Em tempos de debates sobre transgênicos dentro da hegemonia capitalista, os bolivianos ainda mantêm a variabilidade de culturas como quinua, amaranto, peixes e frutas. Estes produtos são ofertados artesanalmente e em pequena escala. Não se tem monopólio nem consumo padronizado (Ibáñez, 2016).

Os alimentos e bebidas artesanais respeitam o calendário agrícola, ou seja, representam um modo alternativo de se alimentar ligado aos ciclos da natureza. Neste sentido, existem também os sistemas de escambo, presentes na Venezuela, Bolívia e Brasil.

Outra forma de praticar o Bem Viver está no uso dado às praças. Ibáñez (2016, p. 330) assim discorre:

[...] As pessoas reocupam as praças com base em outros sentidos. Entram nos jardins e fazem piqueniques, convivem em família, comem, brincam, namoram, fazem grupos. Nas culturas indígenas, os objetos e as coisas não têm fins ornamentais em si: podem ser esteticamente bonitos, mas devem ter uma utilidade prática para ser verdadeiramente "lindos". A beleza é uma espécie de conjunção entre sentido estético e sentido de utilidade. A praça é linda se permite conviver; o jardim é lindo se permite ser usado para essas convivências e relações.

Percebe-se que a cidade é o lugar de realização de processos plurais. Por ser um ambiente vivo, atualmente se encontra em disputa por sentidos. Somente a inquietude é capaz de questionar o imaginário dominante. Por isso, não custa repetir: novas formas de vida, mais saudáveis e menos aceleradas, são possíveis dentro da urbe, mantendo conexão com os saberes indígenas e rurais. Novas formas de gestão social são necessárias desde que acessíveis a todos, assim como já acontece com as praças do Alto José do Pinho e seus alto-falantes da rádio.

Sim, a forma como os povos originários tratam a natureza tem muito a ensinar. A sensibilidade para além da prosperidade material dá espaço para pensar o outro em harmonia com a Mãe Terra. Essa forma de (con)viver é resistência e já indica uma alternativa ao capitalismo.

A cidade não deve ser vestida de um pensamento único. Esse tipo de discurso não interessa à cidade diversa. Pelo contrário, serve à cidade colonial/patriarcal. Não queremos dizer que a economia capitalista será alterada abruptamente, porém ressignificações são feitas nas relações econômicas.

O Bem Viver orienta o tempo presente. As ações vêm acontecendo na conjuntura latino-americana tendo em vista o desgaste do planeta causado pela lógica mercantil. Diante da crise, alternativas surgem da criatividade da população. Por isso, trabalhar a cidade é tão complexo, porque ao lado do colonial, há o rural com sua visão de harmonia. 
Os saberes indígenas/camponeses/rurais questionam noções de riqueza e pobreza e oferecem respostas em meio a tantas vidas sufocadas pelo capitalismo predatório. Entretanto, a tarefa do Bem Viver exige mudança de mentalidade nos âmbitos político, social, econômico e, claro, cultural. Significa precipuamente romper com o capitalismo dominante e com os diversos socialismos reais (Acosta, 2016).

Justamente por se tratar de um horizonte de sentido, sem modelos prontos ou claros, intentou-se relacionar o Bem Viver a outras experimentações sociais, no âmbito da América Latina. O Alto José do Pinho, ao concretizar processos organizativos em bairros populares, não é a única, mas sim uma das múltiplas facetas em torno das alternativas ao desenvolvimento.

\section{CONCLUSÕES}

A proposta de relacionar o Bem Viver enquanto horizonte de sentido às práticas cotidianas do bairro Alto José do Pinho em Recife/PE mostra que a cidade, apesar de possuir matriz colonial, abarca novos modos de vida, baseados nos saberes e filosofias dos povos tradicionais. Diante da crise civilizatória, é necessário observar a maneira como eles tratam a natureza e como se relacionam com os demais, levando em consideração a pluralidade e a igualdade.

Para o padrão ocidental, talvez pareça contraditório, mas as alternativas ao desenvolvimento nascem de lutas populares que pregam justamente a reconfiguração dos imaginários urbanos a partir do reconhecimento da diversidade cultural.

Entre as muitas experiências, especificamente as vividas pelo Alto José do Pinho, todas podem ser chamadas de Bem Viver. A denominação é objeto de inúmeras interpretações, porém algo é comum: os planos de vida formulados vêm das lições de sensibilidade dos grupos marginalizados. Para cada marca da cidade colonial, existe uma proposta de desmercantilizar as relações humanas e questionar o padrão capitalista ocidental a partir de práticas comunitárias de educação ambiental, como o Projeto Alto Sustentável, criado pelos moradores do Alto.

Dentro do espaço urbano, existem experiências e lições responsáveis por manter as singularidades e o sentimento de pertencimento. Há muitos projetos em construção procurando a ressignificação da cidade. Neste sentido, o Bem Viver assume um papel transformador ao recuperar a convivencialidade e a noção de coletividade.

Enquanto ruptura epistêmica, os saberes experienciados no Alto tentam frear a concepção predatória do capital, introjetando um imaginário de gestão coletiva que se associa diretamente ao exercício da cidadania. Estes horizontes que nascem do/no corpo social latino-americano dão esperança e abrem caminhos para se pensar corajosamente em possíveis transições sociais. 


\section{REFERÊNCIAS}

Acosta, Alberto (2016). O Bem Viver: uma oportunidade para imaginar outros mundos. São Paulo: Elefante.

Beltrão, Luiz (2014). Folkcomunicação: um estudo dos agentes e dos meios populares de informação de fatos e expressão de ideias. Porto Alegre: EDIPUCRS.

Ferreira, Eliana Maria Sousa., Sousa, Lucas Casemiro de., \& Lima, Maria Érica de Oliveira (2017). A música como forma de comunicação de Grupos Marginalizados: um estudo da Folkcomunicação. Disponível em: http://anaisfolkcom.redefolkcom.org/index.php/folkcom/ article/view/30.

Ferreira, Simone Raquel Batista (2016). Marcas da colonialidade do poder no conflito entre a mineradora Samarco, os povos originários e comunidades tradicionais do Rio Doce. In: B. Milanez \& C. Losekann (Orgs.), Desastre no Vale do Rio Doce: antecedentes, impactos e ações sobre a destruição, Rio de Janeiro: Folio Digital: Letra e Imagem.

Ibáñez, Mario Rodriguez (2016). Ressignificando a cidade colonial e extrativista. In: G. Dilger, M. Lang \& J. Pereira Filho (Orgs.), Descolonizar o imaginário: debates sobre pós-extrativismo e alternativas ao desenvolvimento, São Paulo: Elefante.

Instituto Brasileiro de Geografia e Estatística - IBGE (2010). Censo Demográfico. Resultados do universo: características da população e domicilios. Disponível em: http://www.ibge.gov.br.

Krenak, Ailton (2020). A vida não é útil. Pesquisa e organização Rita Carelli. 1. ed. São Paulo: Companhia das Letras.

Lander, Edgardo (2016). Com o tempo contado: crise civilizatória, limites do planeta, ataques à democracia e povos em resistência. In: G. Dilger, M. Lang \& J. Pereira Filho (Orgs.), Descolonizar o imaginário: debates sobre pós-extrativismo e alternativas ao desenvolvimento, São Paulo: Elefante.

Lang, Miriam (2016). Introdução: alternativas ao desenvolvimento. In: G. Dilger, M. Lang \& J. Pereira Filho (Orgs.), Descolonizar o imaginário: debates sobre pós-extrativismo e alternativas ao desenvolvimento, São Paulo: Elefante.

Marques, Clarissa (2013). Por uma compreensão da crise ambiental e do paradigma do risco. Revista Caderno de Relações Internacionais, 4(7), 75-95.

Mergulhão, Eliane (2017). Folkcomunicação \& sociedades periféricas: cultura, linguagem e comunicação dos excluídos. Disponível em: http://anaisfolkcom.redefolkcom.org/index.php/folkcom/ article/view/20.

Pontes Júnior, Felício de Araújo \& Barros, Lucivaldo Vasconcelos (2016). A Natureza como sujeito de direitos: a proteção do Rio Xingu em face da construção de Belo Monte. In: G. Dilger, M. Lang \& J. Pereira Filho (Orgs.), Descolonizar o imaginário: debates sobre pós-extrativismo e alternativas ao desenvolvimento, São Paulo: Elefante.

Prefeitura do Recife. Alto José do Pinho. Disponível em: http://www2.recife.pe.gov.br/servico/alto-jose-dopinho?op=NT/4Mg==.

Projeto Alto Sustentável. Instagram: @altosustentavel. Disponível em:

https://www.instagram.com/altosustentavel/.

Santos, Milton (1996). A natureza do espaço: técnica e tempo, razão e emoção. São Paulo: Hucitec.

Sato, Michèle., Gauthier, Jacques., \& Parigipe, Lymbo (2005). Insurgência do grupo pesquisador na educação ambiental sociopoética. In: M. Sato \& I. Carvalho (Orgs.), Educação Ambiental - Pesquisa e Desafios. 1. ed. Porto Alegre: Artmed.

Silva, Ricardo Leite da (2011). Alto José do Pinho: ocupação, instituição e práticas culturais (1940-1960). 214 p. Dissertação (Mestrado em História) Universidade Federal de Pernambuco, Recife. Retrieved from: https://repositorio.ufpe.br/handle/123456789/7584. 